\title{
DEAHP Approach for Manpower Performance Evaluation
}

\author{
Sanjeet Singh $\cdot$ Remica Aggarwal
}

Received: 17 September 2013/Revised: 18 June 2014/ Accepted: 22 July 2014 /

Published online: 9 August 2014

(C) Operations Research Society of China, Periodicals Agency of Shanghai University, and SpringerVerlag Berlin Heidelberg 2014

\begin{abstract}
The manpower in an organization constitutes an important and essential asset. Competent personnel endowed with individual academic and managerial strengths in specific disciplines and personal capabilities, who can undertake a variety of marketing or research assignments, are needed in any organization as they substantially credit to its performance. Development of rational techniques for capability assessment during recruitment of personnel is therefore vital. The techniques that are normally employed for decision making in identification of performance attributes including their weight assignments include techniques like Delphi and decision matrix, Analytic Hierarchy Process (AHP) etc. AHP converts qualitative opinion of experts into quantified values and generates a decision matrix. In this paper, we have integrated Data Envelopment Analysis (DEA) to generate local weights of alternatives from pair-wise comparison of judgment matrix used in the AHP for a three attribute system for measuring performance of personnel at entry level of managerial hierarchy. Multiple expert judgments have been considered for weight determination of the attributes. Thus, DEAHP (i.e., combined DEAAHP approach) has been proposed in this paper as an alternative to the traditional methods of weight derivation in AHP.
\end{abstract}

Keywords DEA $\cdot$ AHP $\cdot$ MCDM $\cdot$ Performance evaluation $\cdot$ Linear programming

\footnotetext{
S. Singh $(\bowtie)$

Operations Management Group, Indian Institute of Management Calcutta, DH Road, Joka, Kolkata 700104, India

e-mail: sanjeet@iimcal.ac.in

R. Aggarwal

Department of Management, Birla Institute of Technology and Science, Pilani 333031, India e-mail: remica_or@rediffmail.com
} 


\section{Introduction}

Workforce constitutes a vital and valuable organizational asset as they are the source of creativity. Implicit knowledge assets of the employees in the organization constitute one of the most crucial elements that affect the work performance of the company. Companies compete for business through the people they employ. It is therefore an aim of any organization to ensure that their greatest asset, albeit the most elusive one, the human capital — the human resources, is utilized to its best and highest use. Performance management is a critical aspect of organizational effectiveness [1]. Because it is the key process through which work is accomplished, it is considered the "Achilles Heel" of managing human capital [2] and should therefore be a top priority of managers [3].

Evaluation of an employee's performance against organizational goals is crucial to understand/determine whether an organization meets its goal satisfactory. Formal performance evaluation or appraisals are required to take human resource decisions related to pay raises, promotions, demotions, terminations etc. It is also necessary to assess an employee's training needs. Manpower performance evaluation through quantitative and qualitative methods is being done by many organizations across the globe. Longenecker and Fink [4] stated the reasons for which performance evaluation is important to organizations. Wu [5] describes performance evaluation as a complex problem, and it involves various kind of judgments about which performance measures to use. Identification of the relevant and important criteria is the critical aspect of employee's performance evaluation [6]. Suwignjo et al. [7] have developed quantitative models for performance measurement systems, a model measuring the performance with respect to a factor. Meyer [8] described the employee evaluation procedure adopted by a nursing home. Chandra [9] cited several problems in employee evaluation, which in his opinion can be easily overcome by following his prescribed guidelines. Taylor III et al. [10] have described a case study where AHP has been used to evaluate personnel for selection. Chan and Lynn [11] have used AHP to propose a model for evaluation of several branches of a firm. Islam and Rasad [12] have done a case study using AHP for employee performance evaluation.

The decision to hire a manger who will be able to "translate business strategy into action" requires clear identification of the criteria (attributes) that distinguish successful from unsuccessful performance and use only predictive measures of success, which are reliable and valid [13]. The choice of selection criteria (performance attributes) should be consistent with the organization's strategic direction and culture. Performance attributes are defined as those qualities which all seniors and program managers are expected to develop and demonstrate in the performance of their responsibilities. Demonstration of these attributes will help to promote a culture of continuous administrative improvement where all are working toward bettering our services and environment. Some of the common performance attributes include leadership skills, strategic thinking, outstanding team and individual performance, responsible risk taking, innovation, learning from experience, identifying and correcting organizational limitations, ability to find root causes, accountability, authority, etc. 
At a practical level, mathematical programming under multiple objectives has emerged as a powerful tool to assist in the process of searching for decisions which best satisfy a multitude of conflicting objectives, and there are a number of distinct methodologies for multi-criteria decision-making problems that exist. These methodologies can be categorized in a variety of ways, such as form of model (e.g., linear, non-linear, and stochastic), characteristics of the decision space (e.g., finite or infinite), or solution process (e.g., prior specification of preferences or interactive). Also for such studies, Saaty [14] suggested a technique called AHP. This management technique has been developed to handle multiple criteria decision-making (MCDM) problems using qualitative evaluation of the systems by experts from relevant disciplines and profession. DEA is one of the most popular non-parametric mathematical programming techniques for performance measurement and benchmarking [15]. The goal of DEA is to determine the productive efficiency of a system or decision-making unit (DMU) by comparing how well the DMU converts inputs into outputs, while the goal of MCDM is to rank and select from a set of alternatives that have conflicting criteria [16]. It has been recognized for more than a decade that the MCDM and DEA formulations coincide if inputs and outputs can be viewed as criteria for performance evaluation, with minimization of inputs and/or maximization of outputs as associated objectives.

In this paper, attributes measuring the performance of employees at different levels of managerial hierarchy have been quantified using AHP technique, and pairwise comparison judgment matrices are then checked for consistency. Thereafter, DEA has been used to generate local weights of alternatives from these judgment matrices. The underlying assumption behind the approach is explained, and some salient features are explored. It is proved that DEA correctly estimates the true weights when applied to a consistent matrix formed using a known set of weights. DEA is further proposed to aggregate the local weights of alternatives in terms of different criteria to compute final weights. Because of the synthesis, the proposed approach is named "Data Envelopment Analytic Hierarchy Process (DEAHP)." Thus, DEAHP proposed by Ramanathan [16] has been used in this paper as an alternative to the traditional methods of weight derivation in AHP.

This paper is organized as follows: Sect. 2 deals with the details of the techniques used i.e., AHP, DEA, and DEAHP. Empirical illustration of the problem, selected to justify the practicality of the approach, is presented in Sect. 3. In Sect. 4, we perform the analysis and present the results using the proposed DEAHP approach. Finally, in Sect. 5, we give the conclusions.

\section{Details of the Techniques: AHP, DEA and DEAHP}

Here, we briefly describe the basics of the techniques used in this paper namely AHP, DEA, and DEAHP.

\subsection{AHP}

Formulation of a managerial problem through AHP requires the following steps. 


\section{Step 1. Structuring of the decision problem into a hierarchical model}

It includes decomposition of the decision problem into elements according to their common characteristics and the formation of a hierarchical model having different levels [14].

Step 2. Making pair-wise comparisons and obtaining the judgment matrix

The elements of a particular level are compared with respect to a specific element in the immediate upper level.

Step 3. Local weights and consistency of comparisons

Local weights of the elements are calculated from the judgment matrices using the eigenvector method (EVM). The normalized eigenvectors corresponding to the principal Eigenvalue of the judgment matrix provide the weights of the corresponding elements. Apart from EVM, other methods proposed in the literature like Logarithmic Least-square technique [17], Goal programming [18], and other methods as in [19] can also be used for calculating weights. When EVM is used, consistency ratio (CR) can be computed. A value of CR less than 0.1 is considered acceptable because human judgments need not be always consistent and there may be inconsistencies introduced because of the nature of scale used. If CR for a matrix is more than 0.1 , then judgments should be elicited once again from the decision maker till he/she gives more consistent judgments [20]. The consistency of judgments received from a number of experts has to be verified for each judgment matrix. The synthesized matrix is generated by taking geometric mean of respondents' judgments for each pair-wise comparison. Therefore, this synthesized matrix can be represented as

$$
\left(\mathrm{a}_{\mathrm{ij}, \mathrm{k}}\right)^{1 / \mathrm{p}},
$$

where $p$ denotes the number of judgments, and $\mathrm{a}_{\mathrm{ij}, \mathrm{k}}$ indicates the judgment $\mathrm{a}_{\mathrm{ij}}$ given by the kth respondent.

Step 4. Aggregation of weights across various levels to obtain the final weights of alternatives

Once the local weights of elements of different levels are obtained, these are aggregated to obtain final weights of the decision alternatives. For example, the final weight of any alternative $A_{1}$ is computed using the following hierarchical (arithmetic) aggregation rule in traditional AHP:

$$
\text { Final Weight of } \begin{aligned}
\mathrm{A}_{1}= & \sum_{j} \text { local weight of } A_{1} \text { with Criterion } C_{j} \\
& \times \text { local weight of Criterion } C_{j} .
\end{aligned}
$$

\subsection{DEA}

DEA is a widely applied non-parametric mathematical programming approach for analyzing the productive efficiency and performance evaluation of decision-making units (DMUs) or firms/alternatives with multiple incomparable inputs and outputs. Based on Farrel's [21] study, DEA was first introduced by Charnes et al. [22]. In recent years, DEA has been applied to a wide spectrum of practical problems such as in units operating production processes [23], supplier selection [24], bank failure prediction [25], commercial and cross regions banks profitability [26-28], portfolio 
evaluation [29], and sports [30]. The objective of the output-oriented DEA model pioneered by Charnes et al. [22] (also known as CCR models) is to maximize outputs while satisfying at most the given input levels. These linear programming models compare a test DMU to its peers. The model searches the data set to determine if some linear combination of the peer DMUs produces higher levels of outputs using at most the given level of inputs of the observing DMU.

For each alternative DMU, the efficiency is measured and an optimization will be proposed according to the below indicated linear program. In DEA, the observed DMU is assigned the most favorable weighting of the inputs/outputs given the constraints. The DMUs are denoted by $j=1,2, \cdots, N$. Each DMU employs $m$ inputs to produce $s$ different outputs. Specifically, DMU $\mathrm{D}_{\mathrm{j}}$ consumes amount $x_{i j}$ of input $i(i=1,2, \cdots, m)$ and produce amount $y_{r j}$ of output $r(r=1,2, \cdots, s)$. It is assumed that $x_{i j} \geqslant 0$ and $y_{r j} \geqslant 0$ and that each DMU has at least one positive input and one positive output value. Let $u_{i}(i=1,2, \cdots, m)$ and $v_{r}(r=1,2, \cdots, s)$ denote the input and output weights, respectively. In DEA, observed input and output values for all DMUs are given, and inputs and output weights are calculated for the observed $\mathrm{DMU}_{0}$ using the following linear programming problem (see e.g., [15]):

$$
\begin{array}{ll}
\text { (P1) } & \text { Maximize } Z_{0}=\sum_{r=1}^{s} v_{r} y_{r 0} \\
& \text { s.t. } \\
& \sum_{i=1}^{m} u_{i} x_{i o}=1, \\
& \sum_{r=1}^{s} v_{r} y_{r j}-\sum_{i=1}^{m} u_{i} x_{i j} \leqslant 0 \quad \text { for } j=1,2, \cdots, N, \\
& u_{i} \geqslant 0 \quad \text { for } i=1,2, \cdots, m, \\
& v_{r} \geqslant 0 \quad \text { for } r=1,2, \cdots, s .
\end{array}
$$

This model can be used to calculate the DEA efficiency score of the observed DMU. The optimal objective function value of problem (P1) represents the efficiency score. This DMU is relatively efficient if and only if its optimal objective function value equals unity. Efficiency scores for inefficient units are between zero and one. For inefficient units, DEA also provides those efficient units (namely peers or benchmarks), which the inefficient units can emulate to register performances that could improve their efficiency scores. This model assumes constant returns to scale (CRS) which is said to prevail when a proportionate increase (decrease) in all inputs leads to same proportionate increase (decrease) in all outputs.

Remark 2.2 To use DEA, the following condition must be satisfied [13]:

$$
n \geqslant \max \{m \times s, 3(m+s)\},
$$

where $n$ is the number of DMU's. In addition, $m$ and $s$ are number of inputs and outputs, respectively. It has been empirically shown that if this condition does not hold, it causes more than one DMUs having efficiency score equal to one. Consequently, it is not possible to discriminate among efficient DMU's. In DEAHP, the number of DMU's is equal to the number of alternatives or criteria $(n)$, and the number of outputs is equal to $n$, and there is one dummy input with a value of one for all DMU's. Therefore, the previous condition will not be satisfied when the 
DEAHP is used to construct weights for inconsistent pair-wise comparison matrices i.e., $n<\max \{n, 3(n+1)\}$. To overcome this problem, the super efficiency model of Anderson and Peterson [31] for discriminating among efficient DMU's is utilized.

\subsection{Data Envelopment Analytic Hierarchy Process (Synthesis of DEA and AHP in Deriving Weights)}

Here, it is proposed that DEA concepts can be used in the last two steps of applying AHP to a decision problem-namely, deriving local weights from a given judgment matrix and aggregating local weights to get final weights. Efficiency calculations using DEA require outputs and inputs. Each row of the judgment matrix is viewed as a DMU, and each column of the judgment matrix is viewed as an output. Thus, a judgment matrix of size $N \times J$ will have $N$ DMUs and $J$ outputs [32]. Note that the entries of the matrix are viewed as outputs as they have the characteristics of outputs. Since DEA models cannot be used entirely with outputs and require at least one input, a dummy input column has been added having input value as one for all DMUs. Figure 1 gives an overview of the traditional AHP and proposed DEA.

It is proposed that the efficiency scores calculated using DEA models could be interpreted as the local weights of the DMUs. When applied to a consistent matrix, for which weights are known, DEA correctly estimates the true weights. While computing the final weights of the main factors as well as the performance rating of employees, following theorem has been used [16]:

Theorem 2.3 Let the local weights of alternatives with respect to different criteria are given by the matrix below:

$$
\left[\begin{array}{cccc}
w_{11} & w_{12} & \cdots & w_{1 J} \\
w_{21} & w_{22} & \cdots & w_{2 J} \\
\cdots & \cdots & \cdots & \cdots \\
w_{N 1} & w_{N 2} & \cdots & w_{N J}
\end{array}\right],
$$

where $w_{i j}$ is the local weight of alternative $i$ with respect to criterion $j$. There are $N$ alternatives and $J$ criteria. If the importance of criteria is incorporated in the form of multipliers $w_{i 1}=d_{1} w_{i j}$ (for all $j=1,2, \cdots, \mathrm{J}$ and $\left.d_{1}=1\right)$, then final weights aggregated using DEA are proportional to the weighted sum $\sum_{j=1}^{J} d_{j} w_{i j}$ for the $i$ th alternative.

\subsection{Why DEAHP is Used in this Paper?}

Data envelopment analytic hierarchy process (DEAHP) has been used in this paper because of its advantages over AHP approach. Both the approaches have been presented to make the comparison. Some of the advantages DEAHP has over AHP are as follows:

- DEAHP satisfies the rule of independence of irrelevant attributes i.e., if an alternative is eliminated from consideration, then the new ordering for the remaining alternatives should be equivalent to the original ordering for the same 
Traditional AHP View

\begin{tabular}{|l|l|l|l|l|}
\hline & Cr 1 & \multicolumn{1}{|c|}{ Cr 2 } & Cr $\mathrm{n}$ \\
\hline ALT1 & 1 & $\mathrm{a}_{12}$ & & $\mathrm{a}_{1 \mathrm{n}}$ \\
\hline ALT2 & $1 / \mathrm{a}_{12}$ & 1 & & $\mathrm{a}_{2 \mathrm{n}}$ \\
\hline$\ldots \ldots$ & $\ldots$ & $\cdots$ & $\cdots$ & $\cdots$ \\
\hline ALTn & $1 / \mathrm{a}_{1 \mathrm{n}}$ & $1 / \mathrm{a}_{2 \mathrm{n}}$ & & 1 \\
\hline
\end{tabular}

Proposed DEA View

\begin{tabular}{|l|l|l|l|l|l|}
\hline & \multicolumn{1}{|c|}{ O1 } & \multicolumn{1}{|c|}{ 2 } & $\cdots$ & O n & $\begin{array}{c}\text { Dummy } \\
\text { input }\end{array}$ \\
\hline DMU1 & 1 & $\mathrm{a}_{12}$ & & $\mathrm{a}_{1 \mathrm{n}}$ & 1 \\
\hline DMU2 & $1 / \mathrm{a}_{12}$ & 1 & & $\mathrm{a}_{2 \mathrm{n}}$ & 1 \\
\hline$\cdots \cdots$ & $\cdots$ & $\cdots$ & $\cdots$ & $\cdots$ & $\cdots$ \\
\hline DMUn & $1 / \mathrm{a}_{1 \mathrm{n}}$ & $1 / \mathrm{a}_{2 \mathrm{n}}$ & & 1 & 1 \\
\hline
\end{tabular}

Fig. 1 A comparison of the traditional AHP view and the proposed DEA view of a judgment matrix (here, ALT denotes the alternative, $\mathrm{Cr}$ denotes criteria, and $\mathrm{O}$ denotes output)

alternatives [32, 33]. This is because in DEAHP, the weights of alternatives (i.e., the efficiency scores) are calculated separately for each alternative using a separate linear programming model.

- While traditional AHP uses arithmetic normalization, no such normalization is done in the DEAHP. The DEAHP weights are calculated relative to the weight of the best-rated alternative.

- DEAHP does not suffer the rank reversal phenomenon when additional alternatives are added to the model.

- DEAHP calculates true weights for consistent judgment matrices. Whereas for inconsistent matrices, it tries to remove inconsistency.

\section{Empirical Illustration}

An organization wants to recruit and assess its employees based on certain set of attributes. Three main attributes viz. Talent and aptitude (TA), Personal qualities and strengths (PQ), and Management skills (MS) have been identified. These attributes constitute 15 subattributes (refer Fig. 2). Recruitment of managerial personnel are made generally at the entry level whereas they can be assessed for higher levels based on their performance and justification to the below-mentioned attributes. The hierarchical structure for performance rating is shown in Fig. 2. The first two levels of the hierarchical structure contain the factors and subfactors affecting employee's performance. In the last level, one indicates the alternatives to be compared which include the employee $(E)$ whose performance has to be evaluated (say E-5, i.e., 5th employee) and some other well-known employees whose performance can be treated as a standard for the comparative rating of E-5 (say E-1, E-2, etc.). Further the hierarchical structure in the above figure gives only few representative subfactors. An exhaustive list of subfactors can be obtained from refs. [34-37].

After structuring the hierarchy of factors affecting the employee performance, opinion of the experts has been obtained on the following issues: 


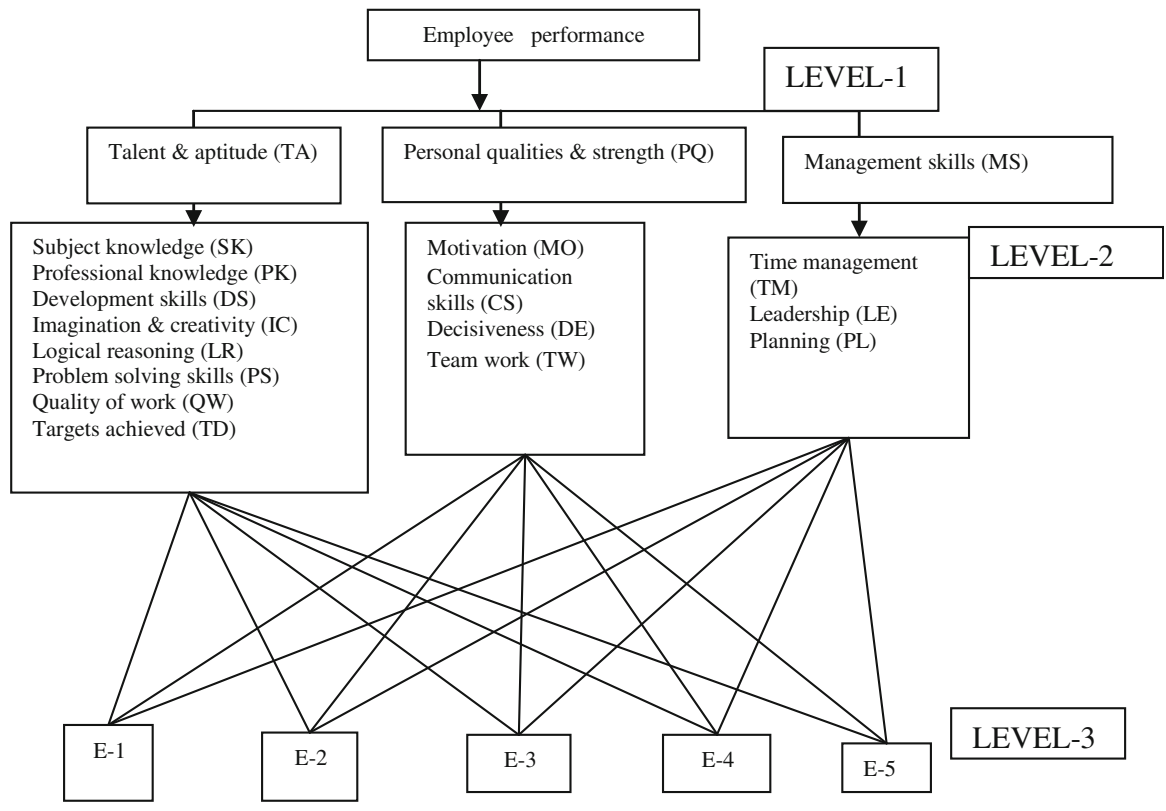

Fig. 2 The hierarchical structure for performance rating

(a) Comparative effects of various factors on the employee performance i.e., talent and aptitude, personal qualities and strengths, and management skills

(b) Comparative contribution of various subfactors on the factors mentioned above

(c) Relative ranking of each employee with respect to each subfactor

The qualitative information is obtained in a suitably designed format enabling pair-wise comparison of factors, subfactors, and employees (refer Table 1). This is communicated in the format by marking ' $\mathrm{X}$ ' appropriately in one of the columns depending on intensity of comparisons i.e., Equal (EQ), Moderate (M), Strong (S), Very Strong (VS), and Extremely Strong (ES). The data obtained in this process are organized into a square matrix whose order is equal to the number of factors being compared at that stage.

Remark 3.3 It has been observed that the variation in expert judgment on the attributes is somewhat large. The respective mean $(\mu)$ and standard deviation $(\sigma)$ have been evaluated, and those judgments which are within $\mu \pm \sigma$ interval are finally considered and their geometric mean has been evaluated employing Eq. (2.1). The judgment matrices (corresponding to the geometric mean values) for various levels of recruitment are given in Table 1 for level 1 of performance hierarchy. By definition, the weights of alternatives and the importance of criteria are normalized so that they sum to unity. 
Table 1 Attributes vis-a-vis employees

\begin{tabular}{|c|c|c|c|c|c|c|c|c|c|c|}
\hline Employees & ES & VS & $\mathrm{S}$ & M & EQ & M & S & VS & ES & Employees \\
\hline E-1 & & & & & & & & & & E-2 \\
\hline E-1 & & & & & $X$ & & & & & E-3 \\
\hline E-1 & & & & & & & & & & E-4 \\
\hline E-1 & & & & & & & & $X$ & & E-5 \\
\hline E-2 & & & & & & & & & & E-3 \\
\hline E-2 & & $X$ & & & & & & & & E-4 \\
\hline E-2 & & & & $X$ & & & & & & E-5 \\
\hline E-3 & & & & & & & & & & E-4 \\
\hline E-3 & & & & & & & & $X$ & & E-5 \\
\hline E-4 & & & & & & & & & $X$ & E-5 \\
\hline
\end{tabular}

Table 2 Evaluation of the relative comparison of employees with respect to subject knowledge (SK)

\begin{tabular}{lllllll}
\hline & E-1 & E-2 & E-3 & E-4 & E-5 & Eigenvalue \\
\hline E-1 & 1 & $1 / 6$ & 1 & 4 & $1 / 7$ & 0.08 \\
E-2 & 6 & 1 & 6 & 7 & 1 & 0.41 \\
E-3 & 1 & $1 / 6$ & 1 & 4 & $1 / 7$ & 0.08 \\
E-4 & $1 / 4$ & $1 / 7$ & $1 / 4$ & 1 & $1 / 9$ & 0.03 \\
E-5 & 7 & 1 & 7 & 9 & 1 & 0.40 \\
\hline
\end{tabular}

Local weights computed for the illustrative judgment matrices using EVM and the corresponding Eigenvalues are shown in Table 2.

\section{Analysis and Results Using DEAHP Approach}

It is proposed that DEA concepts can be used in the last two steps of applying AHP to a decision problem-namely, deriving local weights from a given judgment matrix (Step 3) and aggregating local weights to get final weights. Local weights for the alternatives, i.e., employees (E-1, E-2, E-3, E-4, E-5), have been calculated at Level 3. Level 2 gives the local weights of the subattributes corresponding to the main attribute (Talent and aptitude). Local weights of other two factors (attributes) can be generated in the similar manner. Level 1 provides the local weights of the three main attributes. Final weights can be generated by aggregating the local weights obtained from the previous data for each of the main attribute using DEA approach.

\subsection{Weightages for Alternatives (Level 3 Analysis)}

In the proposed approach, the entries of Table 3 are viewed as the performance (row-wise) of DMUs E-1, E-2, E-3, E-4 and E-5 in terms of five outputs. The output-input structure of DEA is shown in Fig. 1. 
Table 3 Alternatives (employees at level 3) from DEA perspective, subcriteria: subject knowledge

\begin{tabular}{lllllllll}
\hline & E-1 & E-2 & E-3 & E-4 & E-5 & $\begin{array}{l}\text { Input } \\
\text { (dummy) }\end{array}$ & $\begin{array}{l}\text { DEA efficiency(i.e., } \\
\text { weights computed } \\
\text { using DEA approach) }\end{array}$ & $\begin{array}{l}\text { Normalized weight } \\
\text { (through AHP) }\end{array}$ \\
\hline E-1 & 1 & $1 / 6$ & 1 & 4 & $1 / 7$ & 1 & 0.4445 & 0.1951 \\
E-2 & 6 & 1 & 6 & 7 & 1 & 1 & 0.99999 & 1 \\
E-3 & 1 & $1 / 6$ & 1 & 4 & $1 / 7$ & 1 & 0.4445 & 0.1951 \\
E-4 & $1 / 4$ & $1 / 7$ & $1 / 4$ & 1 & $1 / 9$ & 1 & 0.143 & 0.0731 \\
E-5 & 7 & 1 & 7 & 9 & 1 & 1 & 1 & 0.9756 \\
\hline
\end{tabular}

In this case, to get the local weights (i.e., efficiency score in DEA) of the alternative E-1, the following DEA linear programming model (on the lines of problem (P1)) can be formulated:

$$
\begin{array}{ll}
\text { (P2) } & \text { Maximize } \mathrm{Z}_{0}=v_{1}+\frac{1}{6} v_{2}+v_{3}+4 v_{4}+\frac{1}{7} v_{5} \\
& \text { s.t. } \\
& \mathrm{u}_{1}=1 \\
& v_{1}+\frac{1}{6} v_{2}+v_{3}+4 v_{4}+\frac{1}{7} v_{5}-u_{1} \leqslant 0, \\
& 6 v_{1}+v_{2}+6 v_{3}+7 v_{4}+v_{5}-u_{1} \leqslant 0, \\
& v_{1}+\frac{1}{6} v_{2}+v_{3}+4 v_{4}+\frac{1}{7} v_{5}-u_{1} \leqslant 0, \\
& \frac{1}{4} v_{1}+\frac{1}{7} v_{2}+\frac{1}{4} v_{3}+v_{4}+\frac{1}{9} v_{5}-u_{1} \leqslant 0, \\
& 7 v_{1}+v_{2}+7 v_{3}+9 v_{4}+v_{5}-u_{1} \leqslant 0, \\
& v_{1}, v_{2}, v_{3}, v_{4}, v_{5}, u_{1} \geqslant 0 .
\end{array}
$$

The above model (P2) can be easily solved using Excel-Solver or using simplex method. The optimal objective function value of this model will give the local weight of alternative E-1. To get the local weights of other alternatives, problems similar to the above problem (P2) can be formulated and solved. The DEA efficiency scores (i.e., optimal values of the objective function in these problems) representing the local weights of DMUs (i.e., the alternatives here) are presented in the second last column of Table 3. Weights computed using the DEA approach differ from those obtained using EVM. Note that, for comparing with the weights computed by DEA, the local weights obtained using EVM have been be adjusted by dividing all the weights by the largest one, and resulting weights are given in the last column of Table 3 .

Table 3 shows the local weights of employees when compared with respect to subject knowledge criteria. In the similar manner, pair-wise comparisons of the employees with respect to other subcriteria of Talent and Aptitude can be made. In Table 4, an inter comparison of the subfactors displaying Talent and aptitude has been made. These subfactors have been identified using an opinion survey and then again DEAHP approach has been used as in the above manner to compute the local weights of the subfactors also. 
Similarly, comparison of factors affecting personal qualities and strength (PQ) and management skills (MS) can be made.

\subsection{Local Weights of Employees with Respect to Main Criteria (Level 2 Analysis)}

At level 2, three main factors (attributes), namely Talent and Aptitude (TA), Personal qualities and strength (PQ), and Management skills (MS), have been identified and then again the DEAHP approach has been used as in the above manner to compute the local weights of the main factors as shown below in Table 5 .

Level 2 local weights for the employees (E1-E5) can be generated by aggregating the local weights obtained from level 3 for each of the main attribute using DEA approach. For example, for the attribute Talent and Aptitude (TA), level 2 local weights are given in Table 6.

In this case, again the DEA model has been applied. The local weights are considered as outputs of alternatives, and a dummy input is introduced. For example, to get the final weight of alternative E-1, the following DEA linear programming model can be formulated and solved:

(P3) Maximize $\mathrm{Z}_{0}=0.4445 v_{1}+v_{2}+v_{3}+v_{4}+0.45 v_{5}+0.222 v_{6}+0.5 v_{7}+0.2 v_{8}$ s.t.

$$
\begin{aligned}
& u_{1}=1, \\
& 0.4445 v_{1}+v_{2}+v_{3}+v_{4}+0.45 v_{5}+0.222 v_{6}+0.5 v_{7}+0.2 v_{8}-u_{1} \leqslant 0, \\
& v_{1}+0.35294 v_{2}+v_{3}+v_{4}+v_{5}+0.111 v_{6}+v_{7}+v_{8}-u_{1} \leqslant 0, \\
& 0.4445 v_{1}+0.1667 v_{2}+v_{3}+0.6 v_{4}+0.2 v_{5}+v_{6}+0.45 v_{7}+0.45 v_{8}-u_{1} \leqslant 0, \\
& 0.143 v_{1}+v_{2}+v_{3}+0.34 v_{4}+0.14 v_{5}+0.556 v_{6}+0.147+0.145 v_{8}-u_{1} \leqslant 0, \\
& v_{1}+v_{2}+0.1428 v_{3}+0.5312 v_{4}+v_{5}+0.889 v_{6}+v_{7}+v_{8}-u_{1} \leqslant 0, \\
& v_{1}=v_{2} \\
& v_{1}=1.084 v_{3}, \\
& v_{1}=5 v_{4} \\
& v_{1}=v_{5} \\
& v_{1}=v_{6}, \\
& v_{1}=2.5 v_{7}, \\
& v_{1}=2.5 v_{8}, \\
& u_{1}, v_{1}, v_{2}, v_{3}, v_{4}, v_{5}, v_{6}, v_{7}, v_{8} \geqslant 0 .
\end{aligned}
$$

The optimal objective function value of the model (P3) will give the final weight of alternative for the employee E-1. To get the final weight of other alternatives, models similar to the above model should be solved by changing the objective function. Using the values of local weights of subfactors, the additional constraints are introduced in the DEA model (P3) that calculates the final weight (for TA) of DMU (E-1). The resulting final weights of alternatives, which give the talent and aptitude aspect of employees, are given in the last column of Table 6.

The level 2 local weights are proportional to the weighted sum of level 3 local weights. For example, in case of alternative E-1, the weighted sum can be calculated as follows: 


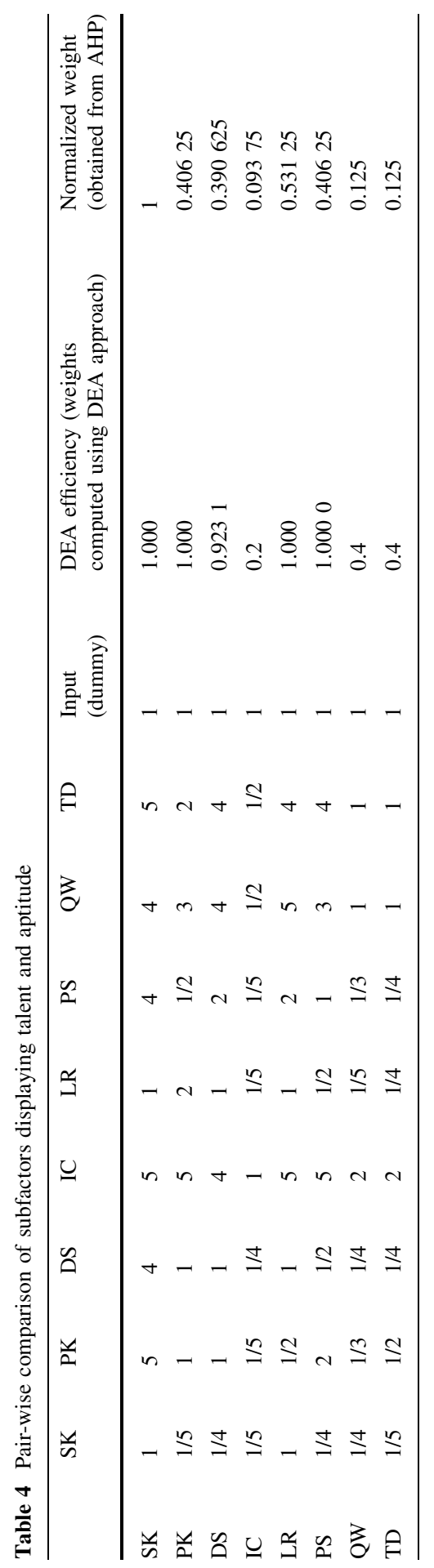


Table 5 Level 2 analysis

\begin{tabular}{lllllll}
\hline & TA & PQ & MS & $\begin{array}{l}\text { Input } \\
\text { (dummy) }\end{array}$ & $\begin{array}{l}\text { DEA efficiency } \\
\text { (weights computed } \\
\text { using DEA approach) }\end{array}$ & $\begin{array}{l}\text { Normalized weight } \\
\text { (obtained from AHP) }\end{array}$ \\
\hline TA & 1 & $1 / 3$ & $1 / 2$ & 1 & 0.334 & 0.2963 \\
$\mathrm{PQ}$ & 3 & 1 & 2 & 1 & 1 & 1 \\
$\mathrm{MS}$ & 2 & $1 / 2$ & 1 & 1 & 0.67 & 0.56 \\
\hline
\end{tabular}

Table 6 Computation of local weights for talent and aptitude (TA)

\begin{tabular}{llllllllll}
\hline Subfactors & SK & PK & DS & IC & LR & PS & QW & TD & $\begin{array}{l}\text { TA (using } \\
\text { DEAHP) }\end{array}$ \\
\hline Relative weightage & 1 & 1 & 0.9231 & 0.2 & 1 & 1 & 0.4 & 0.4 & 0.334 \\
E-1 & 0.4445 & 1 & 1 & 1 & 0.45 & 0.222 & 0.5 & 0.2 & 0.7143 \\
E-2 & 1 & 0.35294 & 1 & 1 & 1 & 0.111 & 1 & 1 & 0.8904 \\
E-3 & 0.4445 & 0.1667 & 1 & 0.6 & 0.2 & 1 & 0.45 & 0.45 & 0.6524 \\
E-4 & 0.143 & 1 & 1 & 0.34 & 0.14 & 0.556 & 0.14 & 0.145 & 0.5975 \\
E-5 & 1 & 1 & 0.1428 & 0.5312 & 1 & 0.889 & 1 & 1 & 1.00 \\
\hline
\end{tabular}

$$
\begin{aligned}
\text { Weighted Sum }= & 0.4445+1+0.9231+0.2+0.45+0.222+0.5 \times 0.4+0.2 \\
& \times 0.4 \\
= & 3.5196
\end{aligned}
$$

Therefore, proceeding on the similar lines, weighted sums for the five employees are $3.5196,4.38704,3.2143,2.9441$ and 4.9271 which are proportional to 0.7143 , $0.8904,0.6524,0.5975$ and 1.00. Similarly, final weights for the other two attributes PQ and MS can also be obtained in the same way.

\subsection{Computation of Final Weights of Employees with Respect to Goal \\ Objective (Level 1 Analysis) and Performance Rating of Employees}

Finally, the performance rating of employees can be computed by again using the same DEAHP approach as discussed in previous sections. In this case, local priorities or the relative weightage of three main factors TA, PQ, and MS are taken into consideration. Performance index of various employees comes out as the final weights of different alternatives (employees E-1, E-2, E-3, E-4 and E-5). Performance rating column in Table 7 compares the performance of an employee (E1) with other employees. This is formed by taking performance index of employee E-1 as 1 (i.e., normalizing employee performance index column with respect to performance index of employee E-1). Similarly, corresponding to other employees (E-2, E-3, E-4 and E-5), performance rating column can be generated.

For example, to get the final weight of employee E-1, the following DEA model has been used: 
Table 7 Performance rating of employees w.r.t. employee E-1 or comparative performance rating

\begin{tabular}{llllll}
\hline Attributes & TA & PQ & MS & $\begin{array}{l}\text { Employee } \\
\text { performance index }\end{array}$ & $\begin{array}{l}\text { Performance } \\
\text { rating }\end{array}$ \\
\hline Relative weightage & 0.334 & 1 & 0.67 & & \\
E-1 & 0.7143 & 0.5 & 0.578 & 0.6538 & 1.0 \\
E-2 & 0.8902 & 1 & 1 & 0.96646 & 1.48 \\
E-3 & 0.6523 & 0.42 & 0.367 & 0.547176 & 0.837 \\
E-4 & 0.5974 & 0.212 & 0.182 & 0.4256 & 0.6509 \\
E-5 & 1.00 & 0.94 & 0.94 & 1.00 & 1.529 \\
\hline
\end{tabular}

(P4) Maximize $Z_{0}=0.7143 v_{1}+0.5 v_{2}+0.578 v_{3}$

s. t.

$u_{1}=1$,

$0.7143 v_{1}+0.5 v_{2}+0.578 v_{3}-u_{1} \leqslant 0$

$0.8902 v_{1}+v_{2}+v_{3}-u_{1} \leqslant 0$

$0.6523 v_{1}+0.42 v_{2}+0.367 v_{3}-u_{1} \leqslant 0$,

$0.5974 v_{1}+0.212 v_{2}+0.182 v_{3}-u_{1} \leqslant 0$,

$v_{1}+0.94 v_{2}+0.94 v_{3}-u_{1} \leqslant 0$,

$v_{1}=3 v_{2}$

$v_{1}=2 v_{3}$

$u_{1}, v_{1}, v_{2}, v_{3} \geqslant 0$.

It can be easily observed from the results of the above analysis that the performance rating of employee E-5 is 1.53 times the performance rating of Employee E-1. For a comparison of cost-effectiveness of two employees, their relative ratings can be used as effectiveness index.

\section{Conclusion}

In this paper, we have used an alternative approach DEAHP to the traditional AHP method for the computation of local weights or priorities and the final weights. For perfectly consistent judgment matrices, this approach gives the similar weights as given by AHP approach where as for inconsistent matrices it tries to remove inconsistency. Further when we compute the final weights, we find that the final weights are weighted sum of local weights. The relative weightage of each factor, viz, talent and aptitude, personal qualities and strengths, and management skills, is suitably aggregated along with the relative weightage of each subfactor and the ratings of each subfactor and the ratings of each alternative (employees) with respect to each subfactor, to give an overall performance index of each employee.

Acknowledgments The authors would like to thank the anonymous reviewers for their critical and constructive comments. 


\section{References}

[1] Cardy, R.L.: Performance management: concepts, skills, and exercises. Armonk, New York (2004)

[2] Pulakos, E.D.: Performance management: a new approach for driving business results. WileyBlackwell, Malden (2009)

[3] Lawler, E.E.: Make human capital a source of competitive advantage. Org. Dyn. 38, 1-7 (2008)

[4] Longenecker, C.O., Fink, L.S.: Creative effective performance appraisals. Ind. Manag. 41(5), 46-55 (1999)

[5] Wu, H.L.: A DEA approach to understanding the performance of Taiwan's steel industries 1970-1996. Asia Pacific Manag. Rev. 10(6), 349-356 (2005)

[6] Sidin, S.M., Hussain, S.R., Soon, T.H.: An exploratory study of factors influencing the college choice decision of undergraduate students in Malaysia. Asia Pacific Manag. Rev. 8(9), 259-280 (2003)

[7] Suwignjo, P., Bititci, U.S., Carrie, A.S.: Qualitative models for performance measurement systems. Int. J. Prod. Econ. 64, 231-241 (2000)

[8] Meyer, A.: An employee evaluation tool that works. Nurs. Homes 44(2), 14-17 (1995)

[9] Chandra, A.: Employee evaluation strategies for healthcare organization-a general trend. Healthcare and public policy 84(2), 34-38 (2006)

[10] Taylor III, F.A., Ketcham, A.F., Hoffman, D.: Personnel evaluation with AHP. Manag. Decis. 36(10), 679-685 (1998)

[11] Chan, Y.C.L., Lynn, B.E.: Performance evaluation and analytic hierarchy process. J. Manag. Acc. Res. 3, 57-87 (1991)

[12] Islam, R., Rasad, S.M.: Employee performance evaluation by the AHP: a case study. Asia Pacific Manag. Rev. 11(3), 163-176 (2006)

[13] Cooper, W.W., Seiford, L.M., Tone, K.: Data envelopment analysis: a comprehensive text with models, applications, references and DEA-solver software. Kluwer Acad. Publ., Boston (2000)

[14] Saaty, T.L.: The analytic hierarchy process: planning, priority setting and resource allocation. McGraw-Hill, New York (1980)

[15] Cooper, W.W., Seiford, L.M., Tone, K.: Data envelopment analysis: a comprehensive text with models, applications, references, and DEA-Solver software. Kluwer Academic Publishers, Dordrecht (2007)

[16] Ramanathan, R.: Data envelopment analysis for weight derivation and aggregation in the analytic hierarchy process. Comput. Oper. Res. 33, 1289-1307 (2006)

[17] Crawford, G., Williams, C.: A note on the analysis of subjective judgment matrices. J. Math. Psychol. 29, 387-405 (1985)

[18] Bryson, N., Joseph, A.: Generating consensus priority point vectors: a logarithmic goal programming approach. Comput. Oper. Res. 26(6), 637-643 (1999)

[19] Choo, E.U., Wedley, W.C.: A common framework for deriving preference values from pair-wise comparison matrices. Comput. Oper. Res. 31(6), 893-908 (2004)

[20] Aczel, J., Saaty, T.L.: Procedure for synthesizing ratio judgments. J. Math. Psychol. 27, 93-102 (1983)

[21] Farrel, M.J.: The measurement of productive efficiency. J. R. Stat. Soc. Series (A) 120, 253-281 (1957)

[22] Charnes, A., Cooper, W.W., Rhodes, E.: Measuring the efficiency of decision making units. Eur. J. Oper. Res. 2, 429-444 (1978)

[23] Emrouznejad, A., Thanassoulis, E.: A mathematical model for dynamic efficiency using data envelopment analysis. Appl. Math. Comput. 160, 363-378 (2005)

[24] Saen, R.F.: A new mathematical approach for suppliers selection: accounting for non-homogeneity is important original research Article. Appl. Math. Comput. 185(1), 84-95 (2007)

[25] Barr, R.S., Siems, T.F.: Bank failure prediction using DEA to measure management quality. In: Barr, R.S., Helgason, R.V., Kennington, J.L. (eds.) Advances in metaheuristics, optimization, and stochastic modeling techniques, pp. 341-365. Kluwer Academic Publishers, Boston (1997)

[26] Jahanshahloo, G.R., Matinb, R.K., Venchehc, A.H.: On return to scale of fully efficient DMUs in data envelopment analysis under interval data. Appl. Math. Comput. 154(1), 31-40 (2004)

[27] Jahanshahloo, F., Hosseinzadeh, L., Shoja, N., Sanei, M., Reza, G.: An alternative approach for equitable allocation of shared costs by using DEA. Appl. Math. Comput. 153(1), 267-274 (2004) 
[28] Desheng, W., Yang, Z., Liang, L.: Efficiency analysis of cross-region bank branches using fuzzy data envelopment analysis. Appl. Math. Comput. 181(1), 271-281 (2005)

[29] Wilkens, K., Zhu, J.: Portfolio evaluation and benchmark selection: a mathematical programming approach. J. Bus. Eco. Stat. 11, 319-323 (2001)

[30] Singh, S.: Measuring the performance of teams in the Indian premier league. Am. J. Oper. Res 1, 180-184 (2011)

[31] Andersen, P., Petersen, N.C.: A procedure for ranking efficient units in data envelopment analysis. Manag. Sci. 39(10), 1261-1264 (1993)

[32] Sinuany-Stern, Z., Abraham, M., Yossi, H.: An AHP/DEA methodology for ranking decision making unit. Int. T. Oper. Res. 7(2), 109-124 (2000)

[33] Ramanathan, R., Ganesh, L.S.: Group preference aggregation methods employed in the AHP: an evaluation and an intrinsic process for deriving members weightages. Eur. J. Oper. Res. 79, 249-265 (1994)

[34] Jereb, E., Rajkovic, U., Rajkovic, V.: A Hierarchical Multiattribute system approach to personnel selection. Int. J. Select. Assess. 13(3), 198-205 (2005)

[35] Becker, B.E., Huselid, M.A., Ulrich, D.: The HR scorecard, p. 235. Harvard Business Scholl Press, Massachusetts (2001)

[36] Bontis, N., Keow, W.C.C., Richardson, S.: Intellectual capital and business performance in Malaysian industries. J. Intellect. Capital. 1, 85-100 (2000)

[37] Abeysekera, I., Guthrie, J.: Human capital reporting in a developing nation. Br. Acc. Rev. 36, 251-268 (2004) 